\title{
O VALOR DEMOCRÁTICO DA PARTICIPAÇÃo NA POLÍTICA CULTURAL SUECA
}

\author{
Sofia Lindström Sol \\ Centro de Estudos de Política Cultural (KPC), Universidade de Borås, Suécia
}

\begin{abstract}
Resumo
Através da exploração da política cultural sueca, este artigo analisa o modo como a política legítima o apoio às artes e à cultura e a "participação" é importante para este processo, discutindo a forma como diferentes entendimentos da cultura e a participação se relacionam com as noções variáveis da governação democrática na cultura. $\mathrm{O}$ artigo discute de que modo um discurso abrangente de cultura considerado positivo e, por conseguinte, de interesse e responsabilidade para a política, pode ser entendido como dois discursos: 1) a cultura é positiva, pois promove coisas boas e 2) a cultura é positiva, pois evita coisas más. Estes dois discursos estão assentes em lógicas diferentes e determinam o conceito de participação de diferentes formas, contudo são construídos como se fossem compatíveis. O significado de governação democrática na cultura é também interpretado de forma diferente nos dois discursos - a proteção da autonomia, igualdade no acesso à cultura e participação como parte integrante são classificadas como democracia corporativista, ao passo que a garantia de sociedades sustentáveis em risco e a participação como igual possibilidade de influência são classificadas como democracia populista. Esta quebra no discurso é interpretada como sinal de redução da legitimidade de um discurso corporativista da democracia, no qual especialistas tiveram o poder de decidir o conteúdo da política cultural. Este artigo integra a discussão sobre o papel da participação e da democracia na política cultural.
\end{abstract}

PALAVRAS-ChAVE

análise de discurso; análise política; corporativismo; populismo

\section{The DEMOCRATIC VALUE OF PARTICIPATION IN SWEDISH CULTURAL POLICY}

\begin{abstract}
Through an exploration of Swedish cultural policy, this article analyses how policy legitimates its support for the arts and culture, and how "participation" is made meaningful in this process, to discuss how different understandings of culture and participation relate to changing notions of democratic governance in culture. The article discusses how an overarching discourse of culture as good, and therefore an interest in and responsibility for policy, can be understood as two discourses: 1) culture is good as it enables good things and 2) culture is good as it prevents bad things. These two discourses rest on different logics and "fixate" the concept of participation in different ways but are constructed as if they were compatible. The meaning of democratic governance in culture is also differently interpreted in the two discourses - as either protection of autonomy, equality in access to culture, and participation as taking part, labelled a corporatist democracy, or as guaranteeing sustainable societies at risk, and participation as an equal possibility to influence, labelled populist democracy. This break in discourse is interpreted as a sign of diminishing legitimacy of a corporatist discourse of democracy where experts have had the
\end{abstract}


power to decide the content of cultural policy. The article partakes in a discussion on the role of participation and democracy in cultural policy.

KEYwORDS

corporatism; discourse analysis; policy analysis, populism

\section{INTRODUÇÃo}

Participação é um conceito bastante utilizado na política cultural (Bonet \& Négrier, 2018; Ekholm \& Lindström Sol, 2019; Jancovich, 2017; Sørensen, 2016; Taylor, 2016). Serve ambições relativamente a vários objetivos da política cultural, tais como atrair uma maior audiência e aumentar o envolvimento do utilizador (Bonet \& Négrier, 2018; Stevenson, Balling \& Kann-Rasmussen, 2017). O conceito envolve questões, tais como: a quem se dirige a cultura, como deveria o financiamento público para a cultura ser legitimado e o que deve ser interpretado como valor e conteúdo da cultura (Carpentier, 2009; Vestheim, 2012). Contudo, a participação continua a ser um "chavão" pouco estudado e sem uma definição exata, apesar de ter uma conotação positiva (Carpentier, 2016).

Como conceito político, a participação é discutida como elemento-chave da democracia, tanto pelo facto de as pessoas serem a fonte de poder, através do voto, como no papel de agentes ativos no exercício do poder, através do diálogo e da influência (Blomgren, 2012; Chhotray \& Stoker, 2012; Pateman, 1970). A atual popularidade da participação é explicada pelo potencial democrático visível, numa altura em que existe um "défice democrático" geral: pouca confiança em relação às instituições democráticas, autoritarismo crescente e diminuição da filiação em organizações e partidos políticos (Chhotray \& Stoker, 2012; Fischer, 2003; Vestheim, 2012). Esta crise na democracia é frequentemente associada a grandes processos de transformação social, tais como a globalização, individualização e transição de um estado-providência para um estado trabalho (workfare) (Fischer, 2003; McGuigan, 2005). Numa tentativa de definir o conceito de participação, Pateman (1970) fez a distinção entre participação parcial e participação total em resposta a académicos que promovem um modelo limitado de democracia - a autora afirma que a participação é essencial para a democracia. Da mesma forma, Arnstein (1969) construiu um modelo de "escada da participação" para compreender o motivo pelo qual determinadas tentativas governamentais de incluir cidadãos em práticas participativas resultaram em não participação, ou pior ainda, em manipulação. Carpentier (2016) analisa um modelo que explica as diferenças entre acesso, interação e participação, em que a última se refere ao envolvimento dos cidadãos na política institucionalizada e não institucionalizada. Enquanto o acesso se refere à mera presença de participantes (e tecnologias), a interação requer relações sociocomunicativas e a participação implica a codecisão. Todas estas teorias ligam a participação ao poder e à influência sobre a tomada de decisão, razão pela qual esta tem fortes ligações ao exercício da democracia. 
O objetivo deste artigo é discutir a importância da participação em relação à governação da cultura. Através da análise do discurso de documentos da política cultural sueca, este estudo defende que estamos na presença de uma mudança no discurso da política cultural. Dependendo da construção da participação, o conceito poderá apoiar ou desafiar noções normativas de procedimentos democráticos na cultura. Deste modo, o artigo junta-se à discussão sobre o papel da participação e da democracia na política cultural, promovida por investigadores, tais como Blomgren (2012), Sørensen (2016) e Vestheim (2009). As questões da investigação incluem: que discursos sobre o papel da cultura na sociedade e, por extensão, sobre a forma "correta" de governar a cultura, aparecem nos documentos de política cultural analisados? A participação faz parte de uma mudança no discurso? De que modo os discursos se relacionam com questões de ideais democráticos?

\section{A governação da CULTURA}

O investigador de política cultural norueguês, Geir Vestheim, definiu a política cultural como o momento em que "os agentes do sistema político intervêm na produção, distribuição e consumo de produtos, serviços e experiências culturais" (Vestheim, 2012, p. 497). Embora a definição das escolhas feitas pelo governo relativamente à cultura não reconheça as políticas implícitas (Ahearne, 2009; Gray, 2012), a definição anterior salienta a relação entre o sistema político e o campo cultural. No seu contestado, mas frequentemente citado, texto de 1989, Hillman-Chartrand e McCaughey defendem uma estrutura de quatro tipos ideais de governação da cultura pelo Estado, nomeadamente, o Estado como facilitador, mecenas/patrono, arquiteto e engenheiro. O Estado-facilitador vê a cultura como um interesse privado e governa principalmente através de deduções fiscais a patrocínios privados. O Estado mecenas/patrono governa através do apoio de conselhos de artes relativamente autónomos, focados na qualidade artística. O princípio de “arm's length", muitas vezes exemplificado pelo British Arts Council, protege o campo das artes da governação política indevida através de uma determinada distância, ou seja, os políticos podem não tomar decisões sobre o conteúdo de instituições culturais ou sobre quem recebe apoio financeiro. Pelo contrário, esta responsabilidade é atribuída a conselhos de artes independentes que recorrem a especialistas na área e, no caso sueco, a organizações e sindicatos do setor das artes, para proteger os valores do mundo da arte. Esta situação moldou a política cultural sueca de forma corporativista (Mangset, 2009). O Estado-arquiteto governa diretamente, através de um departamento cultural, e tende a associar valor cultural a valor social. Por fim, o modelo Estado-engenheiro controla os meios de produção da cultura e instrumentaliza o valor cultural de acordo com os ideais políticos.

A Suécia é um caso interessante para explorar a participação na cultura como conceito político, devido à sua história política cultural. A política cultural da Suécia é concebida como um misto entre Estado mecenas/patrono e arquiteto. O governo estabeleceu um departamento cultural em 1991 e o país conta com uma longa tradição de organizações "arm's length" que determinam a atribuição do financiamento à cultura 
(Blomgren, 2012; Duelund, 2008; Vestheim, 2007). O Estado ocupa-se da cultura, do ensino popular (folkbildning) e dos média, onde a cultura é estritamente definida como "esforços em termos de literatura, artes performativas, artes visuais, música e herança cultural" (Proposition 2009/10:3, p. 12). O Estado governa através de legislação em três áreas: herança cultural, serviços públicos de informação e política relativa a bibliotecas. Tradicionalmente na Suécia, a cultura é vista como parte do interesse público e, como tal, faz parte da expansão do estado-providência após a Segunda Guerra Mundial, responsável pela distribuição do apoio entre Estado, região e municípios. A crise económica dos anos 1990 marcou uma interrupção nesta expansão e a política passou a focar-se cada vez mais na eficácia (Johannisson, 2006). A principal função da política cultural nacional, desde a adoção dos primeiros objetivos da política cultural nacional, em 1974, tem sido a promoção da produção, distribuição e consumo de trabalho artístico profissional e de alta qualidade (Duelund, 2008; Johannisson, 2006). Em geral, na Suécia, as políticas orientadas para a promoção de trabalho e expressão artística são classificadas como política das artes, ao passo que as políticas orientadas para a divulgação da cultura para as pessoas, independentemente de onde residem ou do seu contexto social, são classificadas como política cultural (Blomgren, 2012).

Na Suécia, os municípios são livres na criação de políticas culturais próprias. Ainda assim, estes mostram uma notável consistência na formulação de objetivos que refletem os objetivos da política cultural nacional (Johannisson, 2018). Numa análise comparativa das políticas culturais locais e nacionais, Johannisson e Trépagny (2004) descobriram que os documentos políticos regionais e municipais associam mais explicitamente o valor de cultura ao desenvolvimento sustentável a nível social, económico e ambiental. A política cultural regional e municipal salienta também a necessidade de ultrapassar as fronteiras entre os setores público, privado e civil. Como tal, Johannisson e Trépagny (2004) defendem que a política cultural regional e municipal na Suécia se aproxima mais do modelo arquiteto do que do Estado, que, por sua vez, se aproxima mais do modelo mecenas/ patrono, segundo os modelos formulados por Hillman-Chartrand e McCaughey (1989).

\section{Participação na Políticica Cultural}

Bonet e Négrier (2018) defendem que o discurso participativo emergiu na política cultural nos anos 1970 através do paradigma da democracia cultural, que destaca a cultura amadora, a capacitação dos cidadãos e os direitos das minorias na cultura. Este paradigma surge como crítica a paradigmas anteriores de política cultural que se focavam demasiado estritamente nas belas-artes e assumiam um entendimento universal da preferência e qualidade (Evrard, 1997; Vestheim, 2007; Virolainen, 2016). O paradigma anterior, de democratização cultural, é fundamentado no objetivo da disseminação de cultura de alta qualidade para todos, onde a audiência é maioritariamente considerada consumidora passiva de cultura (Evrard, 1997). Considera-se que a inovação tecnológica e as mudanças no consumo dos média e da cultura pressionaram as instituições culturais para a descoberta de novas formas de envolver a audiência e deixá-la influenciar o 
conteúdo cultural (Bonet \& Négrier, 2018; Virolainen, 2016). A participação não produz um novo paradigma na política cultural, mas é entendida como uma "estratégia que cria tensões entre paradigmas" (Bonet \& Négrier, 2018, p. 70).

Antigamente, a participação na cultura simbolizava uma forma das instituições culturais se tornarem mais acessíveis através do envolvimento/interação com as audiências, sobretudo no que diz respeito a grupos tradicionalmente sub-representados em perfis de visitantes (Bonet \& Négrier, 2018; Virolainen, 2016). Estudos sobre a participação na cultura refletem muitas vezes preocupações de política cultural nacional relativas à desigualdade na participação na cultura com financiamento público (Stevenson et al., 2017; Taylor, 2016; Tomka, 2013). Os números demonstram que as chamadas taxas de participação, quando relativas à participação em artes subsidiadas, estão a decrescer e já foi consistentemente demonstrado que estão relacionadas com o contexto socioeconómico (Stevenson et al., 2017; Taylor, 2016; Vestheim, 2007). Este tipo de não-participação é sobretudo um problema para as instituições que arriscam uma diminuição na legitimidade e cortes no financiamento, e não necessariamente para os cidadãos. Considerar a não-participação como a não-frequência de instituições culturais com financiamento público é um modelo de défice de participação, defendem autores como Sullivan e Miles (2012) e Blomgren (2012).

\section{LEGITIMAR PROCEDIMENTOS DEMOCRÁTICOS NA POLÍTICA CULTURAL}

Gray (2012) discute quatro abordagens possíveis aos procedimentos democráticos na política cultural: democracia direta, democracia representativa, democracia deliberativa e elitismo democrático ou corporativismo (Chhotray \& Stoker, 2012; Fischer, 2003). De acordo com o dicionário Merriam-Webster, corporativismo é a "organização de uma sociedade em corporações industriais e profissionais, que servem como órgãos de representação política e que exercem controlo sobre pessoas e atividades dentro da sua jurisdição"'. Gray (2012) defende que todas as versões da democracia possuem tendências antidemocráticas. A responsabilização democrática e o controlo sobre qualquer destes sistemas são tão válidos como os seus enquadramentos políticos fornecidos pelos políticos eleitos.

Tal como anteriormente referido, o modelo democrático corporativista da política cultural sueca é caracterizado pelo princípio de "arm's length", com o objetivo de proteger as artes da influência política indevida e basear-se na influência de sindicatos artísticos e outras organizações culturais. O sistema de atribuição de decisões relativas ao apoio, através de organizações e especialistas "arm's length", é uma forma de possibilitar a legitimidade em estruturas democráticas, políticas e burocráticas (Vestheim, 2007). O princípio defendido não é apenas a noção democrática liberal clássica de autonomia e liberdade de expressão, mas, acima de tudo, a noção de qualidade artística, implementada com diferentes critérios, como base da tomada de decisão (Blomgren 2012). A influência da política neste modelo democrático pode não derivar tanto do

'Retirado de https://www.merriam-webster.com/dictionary/corporatism 
controlo evidente, mas de uma "comunidade de preferência" entre membros dos organismos "arm's length" e da elite política (Mangset, 2009, p. 276).

O risco de preconceito e corrupção na estrutura corporativista de tomada de decisão deu origem a críticas a este sistema, que é considerado inerentemente não democrático, uma vez que exclui o público devido à sua falta de capital cultural e habitus, que caracteriza as classes mais favorecidas e instruídas (Blomgren, 2012; Vestheim, 2007, p. 231). Como referido por Mangset (2009), a influência dos sindicatos de artistas em organizações "arm's length" tem vindo a diminuir desde os anos 1990, provocando um enfraquecimento da estrutura corporativista da política cultural sueca.

$\mathrm{Na}$ Suécia, pouco se discute sobre a abordagem que deve substituir o modelo corporativista da política cultural, embora se possa argumentar que a vertente participativa tem origem no descontentamento da falta de influência por parte dos cidadãos (Blomgren, 2012; Vestheim, 2007, 2012). O argumento é que a autonomia, enquanto conceito, também se aplica a indivíduos e não só a instituições, pressupondo que a política cultural deve refletir a vontade das pessoas, bem como procurar a legitimação por parte das pessoas e não da elite cultural (Blomgren, 2012; Jancovich, 2017). Neste artigo, o desejado "poder dos cidadãos", que vai contra a estrutura elitista do modelo corporativista (Blomgren, 2012; Chhotray \& Stoker, 2012), é classificado como democracia populista. $O$ populismo é muitas vezes condenado devido às suas associações a movimentos políticos extremistas, porém tanto a democracia populista como a corporativista são "os mecanismos através dos quais os indivíduos podem contribuir para a tomada de decisões em nome de todos os membros do sistema político" (Gray, 2012, p. 505). Ernesto Laclau (2005) entende também as noções de populismo das pessoas não como uma ameaça à democracia, mas como parte essencial dos seus procedimentos. O populismo é uma "lógica política" (Laclau, 2005, p. 117) ou um modo de construir a política por meio de exigências ao sistema, exigências essas que supõem por si só um desvio do status quo, tornando, por conseguinte, possível a emergência de um "povo". Ambas as abordagens democráticas são normalmente compreendidas em termos dos seus extremos: corporativismo como elitismo e populismo como "tirania das massas" (Evrard, 1997).

Neste artigo, a noção de democracia populista não significa necessariamente "uma expressão de antagonismo de classe relativamente a um bloco de poder dominante" (Torfing, 1999, p. 304). Ainda assim, estratégias para reduzir a estrutura corporativista da política cultural sueca foram lançadas pelos próprios "poderosos", tais como os sindicatos artísticos, devido ao seu desejo de não exercer influência indevida (Mangset, 2009). O populismo refere-se, mais propriamente, à importância da participação na política cultural, que leva a uma mudança na atenção dos valores e interesses dos produtores culturais para os interesses dos consumidores de cultura, ou seja, os cidadãos/ contribuintes (Bonet \& Négrier, 2018; Sørensen, 2016). Desde os anos 1990, o foco da política das artes tem mudado, antes concentrada na oferta e agora concentrada na procura (Jancovich, 2017). Já vimos esta mudança no discurso sobre a tomada de decisão participativa em geral e é agora vista como parte integrante da legitimação da ação política na política pública (Fischer, 2003). 
Outra mudança na política cultural atual é o enfoque nas artes como ferramenta para a inclusão social, uma abordagem enraizada na noção instrumental das políticas culturais dos anos 1980 (Stevenson et al., 2015). Segundo McGuigan (2005), a tradução de questões de política social em política cultural é uma característica distintiva dos desenvolvimentos neoliberais no setor público, juntamente com a comercialização, sendo especialmente notória na transmissão nacional. A forma como o neoliberalismo atingiu a política cultural em vários contextos nacionais é contestada, com evidência de que resta um forte compromisso com princípios dos ideais de bildung e resistência a tentativas de instrumentalização (Ekholm \& Lindström Sol, 2019; Virolainen, 2016).

\section{ENQUADRAMENTO TEÓRICO E METODOLÓGICO DO ESTUDO}

Para discutir a importância da participação na política cultural, este artigo recorre a um enquadramento teórico da teoria do discurso, sobretudo como é discutido por Laclau e Mouffe (2001), Torfing (1999), Winther Jørgensen e Phillips (2002). Na teoria do discurso, a importância é atribuída a fenómenos, tais como cultura e participação através da linguagem (Winther Jørgensen \& Phillips, 2002). O entendimento do discurso empregue neste artigo é um sistema de prática de criação de importância que molda visões do mundo e interpretações do que os sujeitos e objetos são e podem ser. O discurso determina a importância através da criação de um enquadramento do que pode ser dito e feito (Torfing, 1999). A teoria do discurso ajuda-nos a entender diferentes interpretações da importância e do valor dos fenómenos, tais como a governação da cultura como negociações entre atores que lutam para ganhar aceitação de determinado entendimento da ordem social (Laclau \& Mouffe, 2001; Torfing, 1999; Winther Jørgensen \& Phillips, 2002).

O principal argumento deste artigo é que existe uma negociação em curso que diz respeito à governação da cultura, ou seja, o interesse do Estado, regiões e municípios no apoio e na aceitação de responsabilidade em relação à cultura e às artes, que resulta numa mudança. $O$ aumento do interesse na participação desempenha um papel nesta mudança. $O$ discurso que pressupõe o interesse político na cultura é o do que a cultura é positiva para a sociedade, uma tendência moral-filosófica atribuível à obra de Aristóteles, De poetica, (Belfiore \& Bennett, 2007). A cultura é tão importante como positiva, de formas diferentes: para a inclusão social, saúde dos cidadãos, entretenimento, lazer, contemplação ou para o seu potencial para a aprendizagem e bildung (Ekholm \& Lindström Sol, 2019). Segundo Belfiore e Bennett (2007), este discurso é dominante, mas sobrepõe-se a dois outros discursos que legitimaram a interferência da política na cultura: a articulação da cultura como negativa (necessidade de censura, pagamento de impostos em determinadas expressões culturais consideradas negativas) e a articulação da cultura como autónoma e que necessita de proteção, relacionada com o sistema de "arm's length" na política cultural, discutido anteriormente. O discurso da autonomia das artes pressupôs uma posição hegemónica (tal como na formação do discurso dominante) da democracia corporativista (Torfing, 1999). Este artigo discute de que modo o discurso abrangente de cultura considerado positivo tem duas componentes: 1) a cultura é positiva, pois promove coisas boas, e 2) a cultura é positiva, pois evita coisas más. 
Estes dois discursos estão assentes em lógicas ligeiramente diferentes e determinam o conceito de participação de diferentes formas.

A teoria do discurso não proporciona - nem o deve fazer - um modo claro e simples de o aplicar em estudos empíricos (Torfing, 1999). A teoria fornece ideias-chave de composições discursivas e coloca o investigador numa posição de bricoleur no empenho analítico (Lindsköld, 2013). Em seguida, será apresentado um breve resumo dos conceitos teóricos principais utilizados na análise da criação de importância da governação democrática da cultura e o papel da participação na vertente material, nomeadamente o mito, o imaginário social, a posição do sujeito, o ponto nodal e o significante vazio.

Um mito não se refere a algo que não é verdadeiro, mas auxilia na desmistificação de suposições que legitimam a criação de importância no discurso (Winther )ørgensen \& Phillips, 2002). Estes são normalmente integrados em conjuntos de normas, valores e pressupostos e são, por vezes, transformados em imaginários sociais - a condição de possibilidade de qualquer objeto (Torfing, 1999). Laclau (1990) exemplifica o imaginário social como sendo o progresso no esclarecimento e na sociedade sem classe no comunismo. O papel, tanto do mito como do imaginário social, é hegemónico: formar objetividade no modo como algo é passível de compreensão e que ações (políticas) são pretendidas e possíveis. Os mitos e os imaginários sociais negam contingência, ou seja, negam a ideia de que as coisas poderiam ser diferentes.

Os discursos proporcionam formas de identidade com as quais os sujeitos se podem identificar. Este processo forma normalmente o espaço dos sujeitos para os atos políticos e para a subjetividade política. Numa estrutura discursiva, os sujeitos são posições do sujeito (Laclau \& Mouffe, 2001; Torfing, 1999). Um discurso pode conter várias posições do sujeito. A título de exemplo, Terning (2016) identifica três posições do sujeito - ou três articulações da posição do sujeito aluno - relativamente ao aluno da política educativa sueca: o aluno livre e bem-sucedido, o aluno individualizado e solitário, e o aluno leal e ajustável.

Os pontos nodais são significantes privilegiados no discurso que servem, em parte, para determinar a importância (Laclau \& Mouffe, 2001). Como exemplo de ponto nodal, no estudo de Lindsköld (2013) sobre a importância da qualidade na política relativa ao financiamento da literatura, a qualidade é um ponto nodal ligado a outros significantes, tais como o original, o moderno e o provocador. Os pontos nodais têm especial capacidade para determinar a importância dos significantes vazios, que transbordam importância e estão articulados de forma diferente dentro de diferentes discursos (Torfing, 1999). A participação é analisada tal como um significante vazio que, por si só, se torna num ponto nodal no discurso nacional, regional e local da política cultural.

\section{DADOS E ANÁLISE}

Esta análise centra-se no modo como os documentos políticos constroem 1) o papel da cultura e, por extensão, legitimam uma governação significativa da cultura, e 2) as definições de participação em relação à criação de importância na governação da cultura 
(Vestheim, 2007). A análise considera quatro documentos de política cultural que definem os objetivos da política cultural e ambições na Suécia (ver Tabela 1). O enfoque do trabalho discursivo em documentos oficiais de política cultural adiciona conhecimentos valiosos ao modo como determinada política é legitimada e porquê (Wedel, Shore, Feldman \& Lathrop, 2005). Suposições, normas e noções normativas subestimadas sobre que tipo de comportamento da sociedade deve ser considerado "certo" e "errado", encontram-se nesses documentos (Lindsköld, 2013; Vestheim, 2007; Wedel et al., 2005). Segundo Vestheim (2007), os documentos políticos oficiais exploram discursos que expressam intenções sobre os efeitos da política cultural. Este estudo considera, portanto, o que Jeremy Ahearne classificou como "política cultural explícita" reconhecida por órgãos políticos, tais como o riksdag (parlamento nacional) sueco ou o comité executivo da cidade (Ahearne, 2009, p. 142).

\begin{tabular}{ll}
\hline \multicolumn{1}{c}{ NíVEL } & \multicolumn{1}{c}{ DoCUMENTO DE POLÍTICA CULTURAL } \\
\hline Nacional & Tid för kultur Prop. 2009/10:3 [Tempo para a cultura] \\
\hline Regional & En mötesplats i världen [Um ponto de encontro no mundo] \\
\hline Municipal & The city of Gothenburg Cultural Programme [Programa cultural da cidade de Gotemburgo] \\
\hline Municipal & $\begin{array}{l}\text { Budget 2018, Cultural Affairs Council Gothenburg [Orçamento 2018, Conselho } \\
\text { dos Assuntos Culturais de Gotemburgo] }\end{array}$ \\
\hline
\end{tabular}

Tabela 1: Material empírico

As políticas culturais locais são normalmente esquecidas na análise política cultural, sobretudo no contexto sueco (Johannisson, 2006, 2018). Neste estudo, a análise considera a política cultural da cidade de Gotemburgo, o segundo maior município da Suécia com aproximadamente 500 mil habitantes. É interessante analisar esta cidade pois é conhecida pela sua política cultural ambiciosa e por ser um dos primeiros municípios a implementar um planeamento cultural, no qual as artes e a cultura foram consideradas como aspetos de uma política social mais geral da cidade (Johannisson, 2006). Os objetivos culturais da cidade de Gotemburgo estão divididos em três subáreas: política das artes, política cultural e planeamento cultural. O orçamento do Conselho de Assuntos Culturais de Gotemburgo é analisado, dado que é formulado com uma visão de como deverá a cultura, enquanto área política, ser melhor governada.

\section{RESULTADOS}

Esta análise refere a articulação de dois componentes do discurso "a cultura é positiva" nos documentos analisados: 1) a cultura é positiva, pois promove coisas boas; e 2) a cultura é positiva, pois evita coisas más (ver Tabela 2). Todos os documentos políticos têm variações dos dois, mas no geral, o primeiro é mais visível nos objetivos da política cultural nacional e local, ao passo que o segundo é mais evidente nos objetivos da política cultural regional e no orçamento local. Por mera conveniência, os dois componentes serão classificados como "discurso" por direito próprio. Os dois discursos estão assentes em diferentes mitos, imaginários sociais e pontos nodais, bem como em posições do sujeito associadas de políticos e habitantes do país, região ou cidade. 
O primeiro discurso salienta o papel da autonomia: a cultura pode funcionar como facilitadora, mas para tal, é necessário que a arte seja livre. A estratégia cultural regional tem cinco dimensões: abertura democrática, qualidade artística, relevância social, potencial económico e caracterização regional. Numa discussão sobre a segunda dimensão, a importância do valor intrínseco das artes na política é clarificada:

a segunda dimensão, a qualidade artística, corresponde ao que frequentemente se denomina política das artes, que em conjunto com a abertura democrática salvaguarda e cria, acima de tudo, pré-requisitos para o valor intrínseco da arte e da liberdade do artista. (Västra Götalandsregionen, 2012, p. 6)

A importância da cultura e da arte livre é sobretudo manifestada no respeito contínuo pelo princípio de "arm's length" e na afirmação do valor da cultura como área política por direito próprio:

a cultura e o conteúdo da cultura não devem - nem podem - ser governados pela tomada de decisão política, mas a sociedade pode, mediante uma política cultural bem executada, criar pré-requisitos para uma esfera cultural forte, capaz de se desenvolver e expandir nas suas próprias condições. (Proposition 2009/10:3, p. 9)

O segundo discurso salienta o papel das artes e da cultura na criação de uma sociedade melhor. $O$ mesmo é expresso em termos de justiça social, importância económica e sustentabilidade social:

na era da concorrência global, é condição de sobrevivência que um pequeno país dependente da exportação como a Suécia - para não falar de uma região voltada para o exterior como a Västra Götaland - procurar uma política cultural forte e trabalhar para ter maior participação na vida cultural. (Västra Götalandsregionen, 2012, p. 11)

Se imaginarmos que a sociedade é um carro, o discurso da "cultura como neutralizadora" entende a cultura como o airbag e a economia como o motor. A estrada está cheia de obstáculos ou ameaças e é necessário adotar uma condução segura. Estas ameaças são a globalização, a desigualdade, a segregação, a estagnação e a insignificância (McGuigan, 2005). No discurso da "cultura como facilitadora", a cultura é compreendida como o volante. Esta imagem indica-nos a posição do condutor: seja como a pessoa que permite que o carro avance ou a pessoa mais cuidadosa e impotente perante os perigos da estrada. A participação pode ser entendida no mínimo como um convite para um passeio de carro ou como envolvimento na decisão sobre que direção tomar. $A$ compreensão dos que não se juntam ao passeio (não participantes) é de que são impedidos a fazê-lo, mas que o fariam se pudessem, ou então, possivelmente não compreenderam a importância do mesmo. Estes discursos sobre a importância da cultura e, desta forma, a importância da política em assumir a responsabilidade pela cultura, seguem 
as linhas clássicas do valor intrínseco ou instrumental da cultura e das artes: a cultura como um valor por direito próprio ou como meio para algo além de si mesmo (Belfiore \& Bennett, 2007; Blomgren, 2012; Vestheim, 2012).

\begin{tabular}{|c|c|c|c|c|c|c|}
\hline Discurso & Miтo & $\begin{array}{l}\text { IMAGINÁRIO } \\
\text { SOCIAL }\end{array}$ & $\begin{array}{l}\text { PoNTOS } \\
\text { NODAIS }\end{array}$ & PosiçõES do SUJEITO & $\begin{array}{l}\text { SIGNIFICANTE VAZIO: } \\
\text { PARTICIPAÇÃo }\end{array}$ & $\begin{array}{l}\text { SIGNIFICANTE } \\
\text { VAZIO: VALOR } \\
\text { DEMOCRÁTICO } \\
\text { NA POLÍTICA } \\
\text { CULTURAI }\end{array}$ \\
\hline $\begin{array}{l}\text { A cultura } \\
\text { como } \\
\text { facilitadora } \\
\text { de coisas } \\
\text { boas. }\end{array}$ & $\begin{array}{l}\text { A cultura } \\
\text { só pode } \\
\text { exercer } \\
\text { uma força } \\
\text { positiva } \\
\text { se as artes } \\
\text { forem livres. } \\
\text { Todos parti- } \\
\text { cipariam na } \\
\text { cultura se } \\
\text { pudessem. }\end{array}$ & $\begin{array}{l}\text { Promover a } \\
\text { sociedade } \\
\text { democrática } \\
\text { através da } \\
\text { garantia de } \\
\text { liberdade } \\
\text { artística. }\end{array}$ & $\begin{array}{l}\text { Liberdade } \\
\text { (respeito). } \\
\text { Igualdade. } \\
\text { Abertura (ao } \\
\text { poder da } \\
\text { cultura). } \\
\text { Fazer parte. }\end{array}$ & $\begin{array}{l}\text { Os que têm capaci- } \\
\text { dade para participar } \\
\text { e os que não têm. } \\
\text { Os que aproveitam } \\
\text { a possibilidade para } \\
\text { exercer influência e os } \\
\text { que não aproveitam. } \\
\text { Política e instituições } \\
\text { culturais que promovem } \\
\text { a cultura e possibilida- } \\
\text { des de participação. } \\
\text { Grupos especiais que } \\
\text { requerem apoio para } \\
\text { a criatividade (jovens, } \\
\text { crianças, sobreposições). }\end{array}$ & $\begin{array}{l}\text { A participação é - } \\
\text { (definição intrínseca) } \\
\text { acesso, ser uma au- } \\
\text { diência e experienciar } \\
\text { (cultura), aprender, } \\
\text { expandir a mente e de- } \\
\text { senvolver capacidades. } \\
\text { (Fazer parte) } \\
\text { Encetar um diálogo, } \\
\text { cooperar, influenciar e } \\
\text { criar (sobreposições). } \\
\text { (Participar, Car- } \\
\text { pentier, 2016) }\end{array}$ & $\begin{array}{l}\text { Proteger a auto- } \\
\text { nomia das artes. } \\
\text { Garantir } \\
\text { igualdade no } \\
\text { acesso a artes } \\
\text { e cultura de } \\
\text { alta qualidade. } \\
\text { (Democratiza- } \\
\text { ção cultural) } \\
\text { (Corporativismo) }\end{array}$ \\
\hline $\begin{array}{l}\text { A cultura } \\
\text { como neu- } \\
\text { tralizadora } \\
\text { de coisas } \\
\text { más. }\end{array}$ & $\begin{array}{l}\text { As so- } \\
\text { ciedades } \\
\text { encontram- } \\
\text {-se num } \\
\text { rápido } \\
\text { processo de } \\
\text { mudança. } \\
\text { Sem a } \\
\text { cultura, } \\
\text { estamos } \\
\text { expostos } \\
\text { ao risco. }\end{array}$ & $\begin{array}{l}\text { Promover } \\
\text { uma socieda- } \\
\text { de democráti- } \\
\text { ca através do } \\
\text { uso da cultura } \\
\text { e das artes. }\end{array}$ & $\begin{array}{l}\text { Mudança } \\
\text { (abertura } \\
\text { para). } \\
\text { Adaptação. } \\
\text { Risco. } \\
\text { Possibilidades. } \\
\text { Influência. }\end{array}$ & $\begin{array}{l}\text { Os que têm possibilida- } \\
\text { des e os que não têm. } \\
\text { Os que são deixados } \\
\text { para trás e os que estão } \\
\text { na linha da frente. }\end{array}$ & $\begin{array}{l}\text { A participação leva a - } \\
\text { (definição instrumental) } \\
\text { Aumento da acessibili- } \\
\text { dade (para determina- } \\
\text { dos grupos), sustenta- } \\
\text { bilidade, coesão social, } \\
\text { inovação, limiares } \\
\text { inferiores, sociedades } \\
\text { abertas, menos discri- } \\
\text { minação e atratividade } \\
\text { numa sociedade em } \\
\text { mudança, repleta de } \\
\text { riscos e desafios. }\end{array}$ & $\begin{array}{l}\text { Garantir socieda- } \\
\text { des sustentáveis } \\
\text { e igualdade de } \\
\text { possibilidades } \\
\text { para exercer } \\
\text { influência nas } \\
\text { pessoas. } \\
\text { (Democracia } \\
\text { cultural) } \\
\text { (Populista) }\end{array}$ \\
\hline
\end{tabular}

Tabela 2: Os dois grandes discursos da política cultural

\section{OS MITOS QUE FUNDAMENTAM OS DOIS DISCURSOS}

Anteriormente, mito foi identificado como sendo as suposições que tornam a criação de importância do discurso possível. Os mitos do discurso da "cultura como facilitadora" referem que as artes podem ser benéficas se forem livres e que todos participariam na vida cultural, se pudessem - se as artes e a cultura fossem mais acessíveis. Isto também nos permite ver a criação da importância da política cultural e a posição do sujeito dos políticos e funcionários públicos no setor das artes, se não fornecessem cultura com infraestruturas e apoio, ainda menos pessoas participariam: 
com o objetivo de aumentar a acessibilidade à cultura, o Comité do Orçamento para Assuntos Culturais está a dar prioridade à busca de várias formas de evitar o surgimento de obstáculos à participação das pessoas na cultura, em condições de igualdade. (Kulturnämnden Göteborg, 2018, p. 15)

Possivelmente, o mito que está na base deste discurso está relacionado com o paradigma de democratização cultural na política cultural indicada por Bonet e Négrier (2018) - a cultura necessita ser disseminada para que chegue às pessoas, garantindo igualdade no acesso. Dado que as artes apenas podem funcionar se forem livres, o imaginário social do discurso é uma sociedade onde políticos promovem mais valores democráticos mediante a autonomia das artes.

Por outro lado, o mito do discurso da "cultura como neutralizadora" aborda a cultura como fornecedora de fatores que previnem o risco e a ameaça, sobretudo ameaças de sustentabilidade, seja a nível nacional, regional ou local:

- "os investimentos na cultura podem, nomeadamente, contribuir para a coesão social através de encontros, maior entendimento e reforço do diálogo entre as pessoas" (Göteborgs Stad 2013, p. 11 [Programa Cultural]);

- "como desenvolver a esfera cultural da região de Västra Götaland enquanto um espaço de fronteira aberta, um espaço de encontro para todos? Como podemos lidar com as tensões da segregação, divisão de classes, desemprego e exclusão? Como tirar partido das possibilidades de criação, experiência, prestação, diálogo intercultural e participação democrática que fazem parte do papel social alargado da cultura?" (Västra Götalandsregionen, 2012, p. 7).

O mito diz-nos que sem cultura perderíamos oportunidades de desenvolver a abertura, o entendimento e o respeito mútuo, e que sem os esforços dos políticos e dos funcionários públicos responsáveis por fornecer cultura aos habitantes, ao país, à região e à cidade arriscaríamos a estagnação, perda de inovação e maior segregação. Portanto, o imaginário social do discurso é uma sociedade em que a prosperidade e a democracia são melhoradas pelo uso da cultura. O imaginário corresponderia possivelmente ao paradigma de democracia cultural na política cultural com enfoque na capacitação dos cidadãos (Bonet \& Négrier, 2018).

\section{Posições DE SUJEITO NOS DISCURSOS}

Os discursos estão organizados de acordo com significantes semelhantes, que por vezes se sobrepõem, mas que ainda assim são distintos (Laclau \& Mouffe, 2001; Terning, 2016). Os jovens e as crianças são uma posição de sujeito importante em todos os documentos políticos e em ambos os discursos, pois representam um grupo que requer intervenções especiais, assim como é o caso dos que vivem em áreas vulneráveis da cidade (Ekholm \& Lindström Sol, 2019): "a administração também se dedicará à procura de métodos estratégicos e novas formas de trabalhar para alcançar novos grupos-alvo e, desta forma, aumentar a acessibilidade a determinados grupos ou áreas geográficas da cidade" (Kulturnämnden Göteborg, 2018, p. 17). 
Devido à política cultural, alguns cidadãos serão capazes de fazer parte da cultura, mas ainda assim existem alguns grupos deixados de parte e que devem ser contemplados nas políticas.

No discurso da "cultura como facilitadora", o financiamento público para a cultura é definido como inquestionável, dado que é uma "responsabilidade social" [Göteborgs Stad, 2013, p. 4 (Programa Cultural)]. O financiamento alternativo e o financiamento da UE são também possíveis, contudo "tais iniciativas devem ser condicionadas pela garantia da integridade, autonomia e valor intrínseco das artes" [Göteborgs Stad, 2013, p. 4 (Programa Cultural)].

No discurso da "cultura como neutralizadora" estão presentes as posições do sujeito das pessoas a quem são dadas oportunidades e dos decisores políticos e funcionários públicos que dão oportunidades para participar na cultura, com um entendimento ligeiramente diferente dos que são deixados para trás. No primeiro discurso, aos que foram deixados para trás não foi dada atenção suficiente por parte dos políticos, ao passo que no segundo discurso, sujeitos como os cidadãos e regiões estão sob o risco de serem deixados para trás por razões intangíveis: "a globalização intensificada significa concorrência num mercado mundial que é implacável para os perdedores. Nada garante que a parte do mundo que normalmente é a mais rica continue a sê-lo" (Västra Götalandsregionen, 2012, p. 7).

As posições de sujeito encontradas nos dois discursos são sobretudo as que permitem/são permitidas pela participação na cultura e as que não permitem/não são permitidas (impedidas de ser). A "culpa" da não participação ou não envolvimento não é normalmente atribuída aos sujeitos em si, mas é explicada por forças externas e muitas vezes vagas, que ultrapassam o controlo (Stevenson et al., 2017) e que, por sua vez, legitimam a intervenção política.

\section{PontoS NODAIS E SIGNIFICANTES VAZIOS EM AMBOS OS DISCURSOS}

Na política cultural, o "significado transbordante" do conceito de participação não é novo. Dada a tendência histórica para uma liderança suave e respeito pelo princípio de "arm's length" na política cultural sueca (Blomgren, 2012; Mangset, 2009), manter conceitos de vários níveis é uma forma de evitar a interferência política indevida (Carpentier, 2009).

Os pontos nodais foram anteriormente discutidos como sinais importantes que determinam, em parte, a importância dos significantes vazios. Os pontos nodais importantes no primeiro discurso são a liberdade, igualdade e fazer parte. Estes significantes afetam os significantes vazios da participação como acesso e o valor democrático como proteção da autonomia e igualdade. A abertura é outro ponto nodal que se refere à capacidade de ser recetivo à força (positiva) da cultura. A abertura é também um ponto nodal, no segundo discurso, porém está mais relacionada com a abertura à mudança. $A$ sociedade em estado de mudança é a ligação importante entre este ponto nodal e o imaginário social deste discurso. Outros pontos nodais importantes são a adaptação (à mudança) e a dualidade do risco/possibilidade que a acompanha. Este ponto nodal determina, parcialmente, 
os significantes vazios da participação como meio para fins sociais e do valor democrático como sociedades sustentáveis e igualdade na possibilidade de influenciar.

Em ambos os discursos, o significante "participação cultural" varia entre um significado mais passivo (fazer parte) e outro mais ativo (participação associada ao poder, Carpentier, 2016), desde o acesso, existência de uma audiência e experiência (da cultura), à aprendizagem, expansão da mente, diálogo, cooperação, influência e criação. $O$ discurso da "cultura como neutralizadora" geralmente emprega o significado dos resultados da participação, que variam entre um aumento da acessibilidade (para determinados grupos) e a sustentabilidade, limiares inferiores, melhores locais de trabalho, menos discriminação e atratividade, numa sociedade em mudança, repleta de riscos e desafios: "Gotemburgo é hoje uma das cidades mais segregadas do país. O trabalho da cidade na implementação das suas políticas cultural e das artes, bem como o planeamento cultural, é crucial para o objetivo de alcançar uma cidade sustentável" (Kulturnämnden Göteborg, 2018, p. 9).

Uma característica que ambos os discursos têm em comum é que a participação é algo a que os habitantes estão primeiramente convidados, ou impedidos de, em vez de ser algo em que devem envolver-se.

Os discursos determinam o significante vazio da participação de forma diferente. No discurso da cultura como facilitadora de coisas boas, a participação é tão importante como um direito democrático. Por exemplo, o princípio do direito a participar na cultura é apoiado pela Declaração dos Direitos da Criança das Nações Unidas em todos os documentos. Quando este discurso tenta estabilizar a importância da participação como meio para um fim, é muitas vezes em termos de "contribuir para a reflexão e o pensamento crítico" (Proposition 2009/10:3, p. 19). No discurso da cultura como neutralizadora de coisas más, a participação torna-se tão importante como instrumental, ou seja, um meio para fins democráticos (Belfiore \& Bennett, 2007). O inimigo do primeiro discurso é a influência política indevida sobre a cultura, ao passo que no segundo discurso, o inimigo é a insignificância global e os efeitos da exclusão social. Ambos os discursos defendem a sua relevância através do apoio em ideais democráticos, tal como mostram estes exemplos:

- “outra forma (de garantir qualidade artística) é defender a distância do princípio de 'arm's length' entre política e arte. A democracia exige que a integridade e a capacidade crítica da arte sejam defendidas" (Västra Götalandsregionen, 2012, p. 14);

- “abertura democrática - ou seja, contribuir para a criação de oportunidades iguais para todos (...) - para participar na cultura como criador, audiência e participante. São necessários mais espaços para permitir que todos os cidadãos participem em debates sobre a política cultural futura"(Västra Götalandsregionen, 2012, p. 14).

O princípio de "arm's length" é, portanto, tão importante como uma relação que engloba a distância necessária entre política e arte, e não entre arte e audiência/cidadãos. Outro significante vazio são os procedimentos democráticos na política cultural, aos quais os diferentes discursos dão importância e contra os quais lutam. O primeiro discurso luta para determinar a importância do valor democrático na política cultural 
defendendo a autonomia das artes da política, ao passo que o segundo discurso luta para determinar a importância do valor democrático na política cultural dando aos cidadãos a possibilidade de influenciar. Tal como o discurso abrangente de cultura é considerado positivo para as sociedades e, por conseguinte, a função para a política alcançou uma posição hegemónica, também o discurso sobre a necessidade de ações políticas se baseia em ideais democráticos.

\section{DisCUSSÃo - O DESEJO DA PARTICIPAÇÃo NA POLÍ́TICA CULTURAL}

O argumento deste artigo é que existe uma quebra no discurso relativo à governação da cultura. O limite da análise é a perspetiva local e nacional, mas esta mudança é discutida de várias formas por outros investigadores (Belfiore \& Bennett, 2007; Bonet \& Négrier, 2018; Duelund, 2008; Jancovich, 2017; Mangset, 2009; Sørensen, 2016; Virolainen, 2016). Este estudo contribui com um exemplo empírico e local para esta mudança, com uma discussão sobre os dois discursos que determina a importância da participação, tanto de uma forma mais intrínseca como mais instrumental.

Um dos resultados desta quebra é que o discurso sobre a cultura é positivo na medida em que evita que coisas más consigam maior legitimidade na política, devido à sua capacidade de dar "expressão discursiva a contradições estruturais subjacentes e dilemas estratégicos no sistema económico e político" (Torfing, 1999, p. 240 e seguintes). Acima de tudo, estes dilemas estão relacionados com questões de exclusão social (Ekholm \& Lindström Sol, 2019). A quebra no discurso pode também ser interpretada como sinal de redução da legitimidade de um discurso corporativista da democracia, no qual os especialistas têm o poder de decidir o conteúdo da política cultural (Mangset, 2009) a favor de um discurso democrático mais populista, no qual os cidadãos ou a audiência são envolvidos num processo de codecisão sobre a política cultural.

Os discursos justificam respostas políticas e os dois discursos encontrados nos documentos analisados conferem legitimidade aos diferentes modos de governar a cultura. O primeiro discurso legitima a continuação do apoio estatal, regional ou municipal às artes através da governação segundo o princípio de "arm's length", ou seja, o status quo (Jancovich, 2017). O segundo discurso também legitima a continuação do apoio estatal, regional ou municipal às artes e à cultura, porém de um modo diferente, mais concretamente através de tentativas de uma governação participativa, ou seja, de mudança. Num mundo que confia cada vez menos nas instituições democráticas e nas taxas de participação distorcidas/decrescentes na cultura com financiamento público, a atualização da participação (na política cultural e em geral) traz consigo a esperança de aprofundar os procedimentos democráticos. $O$ valor da participação reside na maneira como se legitima através das políticas públicas para a cultura, que devem estar em sintonia com os entendimentos dominantes sobre os desafios da sociedade. Que mudanças são legitimadas? Poderá ser demasiado cedo para afirmar, e a resposta não está claramente demonstrada no material analisado, mas poderemos ver algumas mudanças na governação da cultura em matéria de redefinição dos conceitos de cultura, qualidade, representação, audiência e espaços culturais. 
O que é interessante é que os dois discursos não estão construídos como soluções para as falhas do outro, ou seja, não como um conflito antagónico para a hegemonia (Laclau \& Mouffe, 2001), mas sim como se atuassem em complementaridade. O segundo discurso demonstra uma tendência especial para reconhecer a importância do primeiro discurso e de se posicionar como complemento, mas não numa perspetiva de substituição do primeiro. O que parece é um discurso bastante paradoxal relativamente a uma política cultural sobre o entendimento da democracia como forma de governação (Vestheim, 2009). O possível conflito hegemónico é resolvido através da tradicional distinção entre política cultural e política das artes no material analisado (Blomgren, 2012). Nesta distinção, a política das artes - focada na autonomia das artes e no papel do Estado em garantir aos produtores de artes a capacidade de executar obras de alta qualidade - é salvaguardada da política cultural, num cenário político em que a cultura com financiamento público está sob pressão para aliviar os problemas sociais da desigualdade na cidade/região/país.

A questão que se levanta é se a mudança no discurso pode ocorrer sem que haja hegemonia através do antagonismo. Uma leitura de Laclau e Mouffe (2001) propõe uma resposta negativa a esta questão, uma vez que definem as práticas hegemónicas articulatórias como produzidas através de confrontação com outras práticas articulatórias, conferindo-lhes assim uma natureza antagónica. Talvez os dois discursos referidos neste artigo sejam compatíveis, razão pela qual se pode argumentar que a instrumentalização aceitável e não aceitável da cultura possa ser definida de forma relacional, situada num continuum das dificuldades inerentes à governação da cultura (Torfing, 1999). O argumento deste artigo não é a nulidade de um discurso em benefício do outro, nem o artigo defende uma definição mais específica de participação na política cultural. A questão da participação - e da democracia - é ainda mais complexa do isso, e o objetivo da análise é indicar a forma como a luta pela interpretação traz à tona dificuldades na interpretação da ordem social e de respostas políticas adequadas.

\section{SÍNTESE}

Através de uma análise política de dados empíricos provenientes do contexto da política cultural sueca, este artigo visou discutir a importância da participação para a compreensão da governação legítima da cultura e a sua relação com noções da democracia. A análise destacou dois discursos relativos à importância social da cultura: o discurso que permite fenómenos positivos ou o que neutraliza fenómenos negativos no país/região/município. Os dois discursos estabelecem a importância cultural da participação segundo uma lógica intrínseca ou instrumental - como meio para um fim ou como um fim por si só. Reflete, desta forma, uma lógica instrumental/intrínseca clássica na política cultural (Belfiore \& Bennett, 2007; Blomgren, 2012; Vestheim, 2009).

Os dois discursos também definem o significado da governação da cultura de um modo diferente - tanto na proteção da autonomia, igualdade e participação, como no acesso e participação (democracia corporativista), ou na garantia de sociedades sustentáveis em risco e na participação como igualdade na possibilidade de influenciar 
(democracia populista) (Blomgren, 2012; Mangset, 2009). Estes dois entendimentos da democracia (interpretados como o papel do Estado relativamente à cultura e às artes) propostos na análise não são considerados antagónicos no material empírico, mas sim compatíveis. Esta compatibilidade é possível através através do significado atribuído ao "arm's length", um assunto entre as artes e a política, e não entre as artes e a audiência/ as pessoas. Os documentos políticos têm também tendência para separar a política das artes e a política cultural, utilizando por isso discursos diferentes em relação à governação legítima da cultura (Blomgren, 2012).

Tradução: A Inovtrad - Tradução, Formação e Serviços, Unipessoal, Lda.

\section{Agradecimentos}

A realização deste artigo enquadra-se no apoio disponibilizado pela Fundação Sueca para as Humanidades e as Ciências Sociais (referência RMP17-0979:1), pela Universidade de Borås e pelo Departamento de Assuntos Culturais do Município de Gotemburgo.

\section{REFERÊNCIAS}

Ahearne, J. (2009). Cultural policy explicit and implicit: a distinction and some uses. International Journal of Cultural Policy, 15(2), 141-153. https://doi.org/10.1080/10286630902746245

Arnstein, S. (1969). A ladder of citizen participation. Journal of the American Planning Association, 35(4), 216 224. https://doi.org/10.1080/01944366908977225

Belfiore, E. \& Bennett, O. (2007). Rethinking the social impact of the arts. International Journal of Cultural Policy, 13(2), 135-151. https://doi.org/10.1080/10286630701342741

Bonet, L. \& Négrier, E. (2018). The participative turn in cultural policy: paradigms, models, contexts. Poetics, 66, 64-73. https://doi.org/10.1016/j.poetic.2018.02.006

Blomgren, R. (2012). Autonomy or democratic cultural policy: that is the question. International Journal of Cultural Policy, 18(5), 519-529. https://doi.org/10.1080/10286632.2012.708861

Carpentier, N. (2009). Participation is not enough: the conditions of possibility of mediated participatory practices. European Journal of Communication, 24(4), 407-420. https://doi. org/10.1177/0267323109345682

Carpentier, N. (2016). Differentiating between access, interaction and participation. Conjunctions. Transdisciplinary Journal of Cultural Participation, 2(2), 7-28. https://doi.org/10.7146/tjcp.v2i2.23117

Chhotray, V. \& Stoker, G. (2012). Governance theory and practice. A cross-disciplinary approach. Basingstoke: Palgrave MacMillan.

Duelund, P. (2008). Nordic cultural policies: a critical view. International Journal of Cultural Policy, 14(1), 7-24. https://doi.org/10.1080/10286630701856468

Ekholm, D. \& Lindström Sol, S. (2019). Mobilising non-participant youth: using sport and culture in local government policy to target social exclusion. International Journal of Cultural Policy. https://doi.org/10.1 o80/10286632.2019.1595607

Evrard, Y. (1997). Democratizing culture or cultural democracy? The Journal of Arts Management, Law, and Society, 27(3), 167-175. https://doi.org/10.1080/10632929709596961 
Fischer, F. (2003). Reframing public policy: discursive politics and deliberative practices. Nova lorque: Oxford University Press.

Gray, C. (2012). Democratic cultural policy: democratic forms and policy consequences. International Journal of Cultural Policy, 18(5), 505-518. https://doi.org/10.1080/10286632.2012.718911

Göteborgs Stad (2013). Kulturprogram för Göteborgs Stad [Programa Cultural para a cidade de Gotemburgo]. Gotemburgo.

Hillman-Chartrand, H. \& McCaughey, C. (1989). The arm's length principle and the arts: an international perspective - past, present and future. In M.C. Cummings \& J. M. D. Schuster (Eds.), Who's to pay for the Arts? The international search for models of support (pp. 43-80). Nova lorque: American Council for the Arts.

Jancovich, L. (2017). The participation myth. International Journal of Cultural Policy, 23(1), 107-121. https://doi. org/10.1080/10286632.2015.1027698

Johannisson, J. (2006). Det lokala möter världen. Kulturpolitiskt förändringsarbete i 1990-talets Göteborg [Quando o local encontra o global. Mudanças na política cultural de Gotemburgo nos anos 1990] Gotemburgo: Valfrid.

Johannisson, J. (2018). Kulturpolitisk styrning och kulturpolitiska reformer i Sverige [Políticas públicas para a cultura e as reformas culturais na Suécia]. Estocolmo: Kulturanalys Norden.

Johannisson, J. \& Trépagny, V. (2004). The (dis)location of cultural policy: two Swedish cases. Comunicação apresentada no evento The Third International Conference on Cultural Policy Research, em Montreal.

Kulturnämnden Göteborg (2018). Förslag till budget för kulturnämnden 2018, Dnr. 1097/17. [Proposta de Orçamento para o Comité de Assuntos Culturais]. Gotemburgo.

Laclau, E. (2005). On populist reason. Londres: Verso.

Laclau, E. \& Mouffe, C. (2001). Hegemony and socialist strategy: towards a radical democratic politics. Londres: Verso.

Lindsköld, L. (2013). Betydelsen av kvalitet: en studie av diskursen om statens stöd till ny, svensk skönlitteratur 1975-2009. [O significado da qualidade: estudo sobre o apoio do Estado sueco à nova ficção sueca] Borås: Högskolan i Borås.

Mangset, P. (2009). The arm's length principle and the art funding system: a comparative approach. In M. Pyykkönen, N. Simainen \& S. Sokka (Eds.), What about cultural policy? (pp. 273-298). Helsinki/Jyväskylä: Minerva.

McGuigan, J. (2005). Neo-liberalism, culture and policy. International Journal of Cultural Policy, 11(3), $229-241$. https://doi.org/10.1080/10286630500411168

Pateman, C. (1970). Participation and democratic theory. Londres: Cambridge University Press.

Proposition 2009/10:3. Tid för kultur, regeringens proposition [Uma época para a cultura, proposta governativa]. Regeringskansliet, Estocolmo.

Stevenson, D., Balling, G. \& Kann-Rasmussen, N. (2017). Cultural participation in Europe: shared problem or shared problematisation? International Journal of Cultural Policy, 23(1), 89-106. https://doi.org/10.1080/1 0286632.2015.1043290

Sullivan, A. \& Miles, A. (2012). Understanding participation in culture and sport, mixing methods, reordering knowledges. Cultural Trends, 21(4), 311-324. https://doi.org/10.1080/09548963.2012.726795

Sørensen, A.C. (2016). "Participation": the new cultural policy and communication agenda. Nordic Journal of Cultural Policy, 19(1), 4-18. 
Taylor, M. (2016). Nonparticipation or different styles of participation? Alternative interpretations from Taking Part. Cultural Trends, 25(3), 169-181. https://doi.org/10.1080/09548963.2016.1204051

Terning, M. (2016). Myter om gymnasieeleven. En diskursteoretisk studie av dominerande subjektspositoner $i$ politiska texter, 1990-2009 [Mitos na vida de um estudante do Ensino Secundário. Estudo sobre a teoria do discurso dominante nos textos políticos entre 1990-2009]. Tese de doutoramento, Universidade de Estocolmo, Estocolmo, Suécia.

Tomka, G. (2013). Reconceptualizing cultural participation in Europe: grey literature review. Cultural Trends, 22(3-4), 259-264. https://doi.org/10.1080/09548963.2013.819657

Torfing, J. (1999). New theories of discourse: Laclau, Mouffe and Žižek. Oxford: Blackwell.

Vestheim, G. (2007). Cultural policy and democracy: theoretical reflections. International Journal of Cultural Policy, 13(2), 217-235. https://doi.org/10.1080/10286632.2012.708865

Vestheim, G. (2009). The autonomy of culture and the arts - from the Early Bourgeois Era to Late modern 'Runaway World'. In M. Pyykkönen, N. Simainen \& S. Sokka (Eds.), What about cultural policy? (pp. 3153). Helsínquia/Jyväskylä: Minerva.

Vestheim, G. (2012). Cultural policy and democracy: an introduction. International Journal of Cultural Policy, 18(5), 493-504. https://doi.org/10.1080/10286632.2012.708865

Virolainen, J. (2016). Participative turn in cultural policy? An analysis of the concept of cultural participation in Finnish cultural policy. Nordic Journal of Cultural Policy, 19(1), 59-77. Retirado de https://www.idunn. no/nkt/2016/o1/participatory_turn_in_culturalpolicy_-_an_analysis_of_the.

Västra Götalandsregionen (2012). En mötesplats i världen. Kulturstrategi för Västra Götaland 2012 [Um ponto de encontro no mundo. Estratégia cultural para a região de Västra Götaland 2012]. Vänersborg: Västra Götalandsregionen.

Wedel, J. R., Shore, C., Feldman, G. \& Lathrop, S. (2005). Toward an Anthropology of public policy. The ANNALS of the American Academy of Political and Social Science, 6oo(1), 30-51. https://doi. org/10.1177/0002716205276734

Winther Jørgensen, M. \& Phillips, L. (2002). Discourse analysis as theory and method. Londres: Sage.

\section{NOTA BIOGRÁFICA}

Sofia Lindström Sol é investigadora de pós-doutoramento na Universidade de Borås, no Centro de Estudos de Política Cultural (KPC). Atualmente desenvolve um projeto de investigação sobre os processos e métodos participativos na política cultural local. Os seus interesses de investigação englobam as políticas culturais locais, a gestão do património artístico, o ensino das artes e o profissionalismo artístico.

ORCID: https://orcid.org/oooo-0003-4331-4950

Email: sofia.lindstrom@hb.se

Morada: Universidade de Borås - Departamento de Assuntos Culturais, Norra, Hamngatan 8, 41114 Gotemburgo - Suécia

\section{* Submetido: 21/01/2019}

* Aceite: 30/03/2019 